\title{
Computer to Achieve High Efficiency of Office Automation Jin Zhang
}

Jiangxi garment college, School of management, Nanchang, jiangxi

190878023@qq.com

Keywords: Office operation automation; Computer application technology; Work efficiency; Application

\begin{abstract}
The rapid updating of the level of modern science and technology, in the promotion of office automation under the premise of the computer into the office operation process throughout the work. This paper mainly introduces the characteristics and functions of office automation, as well as the development and advantages of new technologies in the actual office. And continue to focus on computer technology in the office operation of the gradual update and development.
\end{abstract}

\section{Introduction}

Information construction in the current office environment has been achieved. In order to improve the efficiency of office, streamlining office time, a comprehensive display of computer information capabilities, the official role of computer application information capabilities. The typical symbol of the new era is the computer information system, the modern office function has formed an unprecedented influence, the advantages of office automation is not only conducive to information management control can also streamline the optimization of office work procedures.

\section{First, Office Automation}

\section{The Concept of Automation Office}

The concept of office automation is the use of office automation equipment. The two main parts are two important features of transactional automation and information processing automation. And vigorously promote the use of computer technology in automatic office, save information and repair and update system functions, making the computer system in the sharing of resources, finishing and information resources to facilitate the collection of ways to ensure. Although e-commerce and automatic office in China to promote soon, but in our work has shown significant high-energy office effectiveness. System and people complement each other's programs, making daily life more intelligent, intelligent advantages in the transmission process reflects a very significant effect. Modern science era constantly updated process, its advantages and characteristics to be used, and achieved a positive direction of development.

\section{The Application of Computer Technology in Office Automation}

Computer application technology in the text and digital functions in dealing with automated office plays a role. For example, Word, W PS and other editor to deal with the text editing and layout design for image processing, the application of these office software to streamline the office hours, while office efficiency to improve. Excel for the completion of the table design, operation of the process, the application of multimedia equipment also makes fax, audio and video business closer to life, making it more visual and modern. With the rapid modernization of the modern scientific level, the rapid development of network technology, the advantage is to enhance the efficiency of office, greatly saving time.

\section{Second, the Advantages of Office Automation in the Information System}

\section{Integrated Office Advantage}

Computer information system makes the office business more holistic, as a platform for conveying information and communication resources, to build a computer online communication convenience. Applied to the larger enterprise work, out of the large number of enterprises, the traditional office 
work and work practices greatly limit the efficiency. The application of computer information system can make each office environment connected, so that the service approach more holistic, improve the internal information flow speed and efficiency, the overall advantages of the obvious reflected.

\section{Data Consolidation Advantages}

The advantages of computer information integration are reflected in the office, which shortens the time of the office process line, and can complete various types of business in the same computer system. Integrated management application computer information system, for example, in the procurement of office to the storage process, the abolition of the office business operations redundant links, the effective use of computer resources to collect and better serve the high efficiency of office operations.

\section{Reflects the Advantages of Green}

The purpose of paperless office is to reduce the waste of office resources, but also can better fit the information exchange of office means to enhance the modern enterprise office in the concept of energy and environmental protection, reduce the waste of office resources, effectively enhance the rational use of resources, Office can also become environmental protection work.

\section{Third, the Computer Information System in the Practical Application of Office}

\section{Information Transmission Technology}

Office communication in the quality of a higher demand, office applications such as the use of windows system operation, computer information transmission technology must be consistent with such systems, examples of communication software BWN3.24F / D it can provide excellent services for office communications, and It also features fax and EDL. It can send fax documents in the order of office address book, you can print fax pictures directly. EDL is a remote communication, its advantage is that in a short time to achieve the rapid transmission of information, the staff of remote operation to send information files, so that the characteristics of office information interaction significantly in the office environment, the application of a wide range.

\section{Wireless Network Technology Applications}

With the powerful influence of the Internet and the support of the computer system, the office network breaks the traditional way of office and has a significant effect in expanding the space and time in the office environment. Wireless network technology enables the staff to share information in the network environment, is the office network development trend. Wireless network technology greatly protect the effectiveness of the office, not only optimize the computer operation on the office work changes, the better is the implementation of the network technology in the role of office. Wireless network technology can help management, operation and many other office business, to become the development trend of office network.

\section{Office Intelligence}

Automated office means greatly promote the development of intelligent office, so that enterprises more convenient to organize the necessary information, better for multi-directional work development to provide resources and information services. The computer information system can provide all-pass service plan and service strategy. For example: to meet the needs of users, the office of the use of intelligent software provides a lot of information resources.

\section{Advantages of Office Video Technology}

Video technology in video surveillance, video conferencing is the most common, is the office intelligent technology and a new upgrade, the use of video for office operations broke through the simple and fragmented working conditions, more convenient for multi-party communication and remote contact, which is a more Intuitive way of office, and provide a platform for remote communication. Video technology is developed on the basis of computer information system, breaking the limitations of traditional meetings, changing the communication environment, providing convenient and efficient means of communication for meetings, and becoming a more common type of communication in modern office environment. 


\section{Fourth, Office Automation Technology in the Modern Management System in the Impact and Development}

In the rapid development of science and technology today, computer technology to help services in office operations is becoming increasingly important, digital information technology is the future direction of development, computer technology will also be the main office work in the office, in the electronic high-speed Information technology today, the computer technology is the core of future work, you can quickly collect and send information, organize resources, diversified work pathways, which will vigorously promote the office automation in full swing.

Office information storage system combines the development trend of cloud storage technology, making office information technology to large space development, but also greatly improved the office space in the use of storage technology. Efficient promotion of office technology information system services, but also for large data of the information age development.

Office software will be with the office information system requirements more and more, the function will be more and more strong, the development of office automation software, the use of a wide range of software to ensure that office automation information can be fully integrated storage.

Multi-module office automation software, in the computer information system has yet to be developed more mature, some office state can not popular office automation software applications, and some still stay in the simple use of computer technology, so vigorously develop office automation software Technology in the application of office operations is conducive to the urgent needs of office business development, to promote the computer technology in the development of office information, but also optimize the efficiency of the office.

\section{Concluding Remarks}

In the current development of the technical society, social progress and the development of science and technology are closely related to the assessment of the management of the enterprise is the management of information management and processing, managers should continue to actively improve the modern and innovative office, this is the office The advantage of automation. Office automation of the important components, including computer text, data processing functions, is an important application of business office. To ensure the efficient operation of enterprises should also focus on the quality of personnel training technology to promote the operation of enterprise automation. This is the future development trend of office, but also to improve the comprehensive ability of enterprises focus.

Science and technology in the office environment in the automation of intelligent operation, the need for computer system applications, through the use of computer systems to improve office efficiency, the rapid development of computer information system applications, in the provision of information technology applications show great potential The The advantages of computer application technology has been fully reflected.

\section{Acknowledgements}

Fund Project: 2016 Jiangxi Provincial Department of Science and Technology Research Project "modern digital pattern technology innovation traditional tie-dye process research" stage results, the project number: GJJ161204.

\section{References}

[1] Gu Wei. Computer information processing technology in office automation application [J]. Talent, 2013 (06): 333.

[2] Chen Yuejie. Township government office automation system design and implementation [D]. University of Electronic Science and Technology, 2012.

[3] $\mathrm{Hu}$ Yunfei. Computer information transmission technology in office automation application [J]. Henan Science and Technology, 2012 (22): 2. 
[4] Hu Yong, Shen Hongping. Study on office automation based on computer information transmission technology [J] .Computer CD-ROM Software and Application, 2014 (07): 123-124.

[5] Liang Yan. Jilin Province, the general college students computer office automation examination reform [J]. Information Systems Engineering, 2014.

[6] Liu Xianghui. Computer information processing technology in office automation application [J]. Software, 2013.

[7] $\mathrm{Yu} \mathrm{Xi}$. Office automation is to improve the level of statistical management of medical records [J]. Office business, 2014.

[8] Computer technology in office automation in the application of the method [J]. Bian Liqing. Science and Technology Innovation and Application. 2015 (23)

[9] Office automation in the application of computer technology research and research [J]. Xia Chunmei. Value Engineering. 2014 (36)

[10] Computer technology in office automation in the application and research [J] .Zhouxu Nan. Heilongjiang Science and Technology Information. 2014 (32) 